Conclusions Studies showed that in children with chronic gastritis, Epstein-Barr virus markers are detected in the blood with high frequency. There is a relationship between the presence of the Epstein-Barr virus in the gastric mucosa and histological signs of gastritis.

\section{GP177 ASSESSMENT OF NUTRITIONAL AND IRON STATUS OF HELICOBACTER PYLORI INFECTED CHILDREN - A SINGLE CENTER STUDY}

${ }^{1}$ Luiza Bordei, 'Victoria Hurduc, ${ }^{1}$ Doina Anca Plesca*. 'Victor Gomoiu Clinical Children's Hospital, 'Carol Davila', University Of Medicine and Pharmacy, Bucharest, Romania; ${ }^{2}$ Victor Gomoiu Clinical Children's Hospital, 'Carol Davila', University Of Medicine and Pharmacy, Bucharest, Romania

10.1136/archdischild-2019-epa.238

Introduction Helicobacter pylori ( $H$ pylori) infection affects about $30 \%$ to two-thirds of human populations and is usually acquired in early childhood. There are conflicting results regarding the nutritional effects of $H$ pylori infection in children mostly about the reduced bioavailability of essential nutrients with growth impairment.

The association between $\mathrm{H}$ pylori infection and iron deficiency anaemia is of considerable current interest.

Objectives To evaluate the effects of $H$ pylori infection on the nutritional and the iron status of symptomatic children that required a first upper endoscopic evaluation.

Methods This was an observational prospective study of 649 symptomatic children (age range 6 months-18 years) mostly with uninvestigated dyspepsia or extradigestive signs, admitted in our unit, from January 2015 to December 2017. Weight, height, body mass index for age and sex were used according to growth charts provided by WHO, 2007. Romania is in a nutritional transition and does not have updated national growth charts. $\mathrm{H}$ pylori infection was documented by at least two standard invasive tests. Hematologic parameters and nutritional status were compared in patients with and without $H$ pylori infection.

Results Active $H$ pylori infection was documented in mostly of studied patients $(63,64 \%)$. The majority of patients presented normal nutritional status $(67,32 \%)$, with a significant proportion of wasting $(12,63 \%)$ associated with risk to underweight $(13,09 \%)$ overweight $(4,48 \%)$ and obesity $(2.16 \%)$. The prevalence of undernutrition was higher in uninfected $\mathrm{H}$ pylori children compared with the infected ones $(13,55 \%$ versus $12,1 \% ; p=0,67)$. Overnutrition prevalence was higher in the case of the $\mathrm{H}$ pylori negative children compared to the positive ones $(3,81 \%$ versus $2,66 \%, p=0,37)$. The stunted was observed only in $3.08 \%$ cases. Iron deficiency anaemia was found in $19,72 \%$, with an approximately the same prevalence in uninfected compared to infected children $(19,91 \%$ versus 19,61\%).

Conclusions The $H$ pylori prevalence rate $(63,64 \%)$ revealed by our study suggests that this infection remains a semnificative problem in our country. This endoscopic series revealed a lower prevalence of undernutrition and overnutrition in symptomatic $H$ pylori infected children compared with uninfected ones, but without statistically signification for the both ends of the spectrum of poor nutritional status. Our study showed that the prevalence of iron deficiency anaemia was not significantly higher in uninfected $\mathrm{H}$ pylori children compared to infected pacients. According to other observational studies the role and the impact of $\mathrm{H}$ pylori infection on growth and iron deficiency anaemia remains controversial.

\section{GP178 MORPHOLOGICAL FEATURES OF CHRONIC ESOPHAGITIS IN CHILDREN WITH CONCOMITANT ALLERGIC DISEASES ARE INTERRELATED WITH THE LEVEL OF CYTOKINES AND NEUROPEPTIDES}

${ }^{1}$ valeria novikova*, ${ }^{2}$ Nikolay Anichkov, ${ }^{2}$ Elena Nevskaia, ${ }^{1}$ Anastasia Listopadova, ${ }^{1,2}$ Yulia Zamiatina, ${ }^{1}$ Olga Gurina, ${ }^{1}$ Olga Varlamova, ${ }^{1}$ Aleksey Blinov. ${ }^{1}$ St. Petersburg State Pediatric Medical University, Saint Petersburg, Russian Federation; ${ }^{2}$ North-Western State Medical University named after I.I. Mechnikov, Saint Petersburg, Russian Federation

10.1136/archdischild-2019-epa.239

Introduction IgE-mediated as well as non-IgE-mediated inflammation to the mucous membranes of the gastrointestinal tract is possible in children with allergic diseases. Purpose of the study: We investigated the morphological features of chronic esophagitis in children with atopic dermatitis (AtD) and bronchial asthma (BA) taking in account the cytokine status (IL-4, IL-5 and IL-13), the level of markers of eosinophilic inflammation (eosinophilic cationic ECP protein and eosinophilic neurotoxin EDN) and neuropeptides (neuropeptide Y (NPY) and substance $\mathrm{P}(\mathrm{SP})$ ).

Patients and methods Study included 61 children (mean age $13.9 \pm 2.36$ years) having morphologically verified chronic esophagitis. 20 children suffered from concomitant AtD, 21 had esophagitis with BA. 20 children had esophagitis without concomitant atopic diseases. All children have undergone esophagogastroduodenoscopy and sampling of mucosal biopsy material from the middle third of the esophagus. Histologically we evaluated dystrophic, regenerative, inflammatory changes, vascular disorders and defects of the mucous membrane. In all children, the level of total IgE was determined and a blood test for IL-4, IL-5 and IL-13, ECP, EDN, NPY and SP was performed by ELISA. The statistical results were estimated by use of the program Stat Soft Statistica 12.0. for Windows- 10.

Research results Morphological features of esophagitis in all studied groups equally frequent. The average level of total $\mathrm{IgE}$ in children with AtD and esophagitis was 186.6 $\pm 126.6 \mathrm{U} / \mathrm{ml}$; in the group of children with BA was $331,5 \pm 238,6 \mathrm{U} / \mathrm{ml}$. All children with esophagitis without atopic diseases had a level of total IgE within the normal range. In AtD, IL-4 levels $(1.08 \pm 0.47 \mathrm{pg} / \mathrm{ml}$ and $1.91 \pm 0.88 \mathrm{pg} / \mathrm{ml}, \mathrm{p}<0.05)$, IL-5 (21.39 $\pm 15.47 \mathrm{pg} / \mathrm{ml}$ and $1.91 \pm 0.88 \mathrm{pg} / \mathrm{ml}, \mathrm{p}<0.05)$, IL-13 (1.72 $\pm 1.55 \mathrm{pg} /$ $\mathrm{ml}$ and $12.11 \pm 6.10 \mathrm{pg} / \mathrm{ml}, \mathrm{p}<0.05), \mathrm{EDN}(47.70 \pm$ $34.83 \mathrm{pg} / \mathrm{ml}$ and $119.00 \pm 64.26 \mathrm{pg} / \mathrm{ml}, \mathrm{p}<0.05)$ and NPY $(40.62 \pm 20.55 \mathrm{pg} / \mathrm{ml}$ and $160.44 \pm 144.44 \mathrm{pg} / \mathrm{ml}$, $\mathrm{p}<0.005$ ) were lower than with the combination of esophagitis with BA and had no differences with the group of children without atopy. Correlative relationship between morphological and immunological parameters in patients with atopy was found.

Conclusion Esophagitis in children with bronchial asthma is accompanied by higher levels of IgE and more pronounced changes in cytokine status than in atopic dermatitis. The correlative relationships between morphological and 